ON THE RECORD

\section{('Requires belief.)}

Footnote to a statement about the placebo effect on the FairDeal Homeopathy website.

\section{NUMBER CRUNCH}

1.8 metres is the average height of Dutch men, thought to be the world's tallest people, since 2001

\subsection{3 metres is the}

average increase in the height of Dutch men from the 1980s to 2000.

0 metres is the change in average height since 2001, leading researchers to conclude that the Dutch have stopped growing.

\section{SCORECARD}

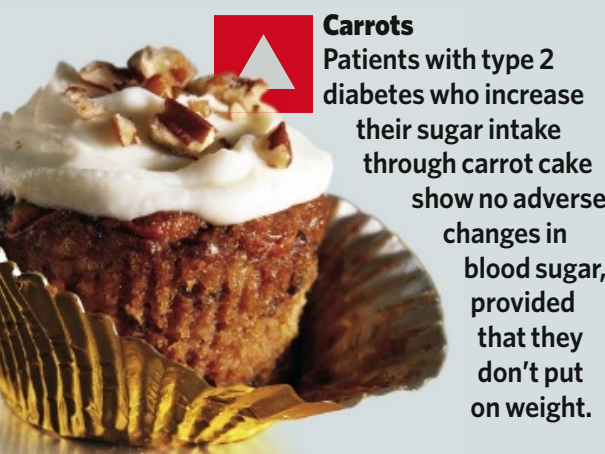

\section{Dull vegetables Encouraging farmers to grow shiny crops instead of matt ones could reduce a region's maximum daytime temperature by $1.9^{\circ} \mathrm{C}$ and fight global warming.}

\section{ZOO NEWS}

\section{Avoiding Knut-mania}

After declaring that it would avoid the media's obsession with Knut and allow its own newborn polar bear cubs to starve, Germany's Nuremberg Zoo has had a radical change of heart. It has helped set up a website dedicated to cute images of the surviving fourweek-old cub, inviting the public to name the little star. The site is getting 15 name suggestions a minute, leading Sidelines to wonder if the zoo's daily news conferences on the cub will be enough to satisfy its fanbase.

Sources: www.fdhom.co.uk, AP, The Sugar Bureau, The Guardian

\title{
Europe to capture carbon
}

New power stations across Europe could be routinely fitted with carbon-dioxide capture and storage (CCS) technology within two years under a proposal by the European Commission.

Next week, the commission will propose a directive on geological storage of $\mathrm{CO}_{2}$ that would require all new fossil-fuel combustion plants to have "suitable space on the installation site for the equipment necessary to capture and compress $\mathrm{CO}_{2}$ ". Builders of new plants would need to assess the availability of "suitable storage sites and the technical feasibility of CCS retrofit" before being granted construction licences. If the European Parliament and Council approve the proposal, it could become law in the European Union's 27 member states as early as 2009.

Champions of CCS applaud the move as a milestone. "We would have hoped for a specific date for CCS to become mandatory," says Paal Frisvold, chair of Bellona Europa, a Norway-based environmental group. "But even so, we do think that the proposed directive is an absolutely crucial step towards making industrial-scale CCS a reality."

Experts think that CCS could reduce global $\mathrm{CO}_{2}$ emissions by one-third by 2050 , if widely deployed. The proposal is in line with the European Commission's Strategic Energy Technology Plan, released last November, which prioritized development and commercial deployment of CCS to reduce emissions in Europe.

The proposed directive is the first attempt anywhere in the world to provide a comprehensive legal framework for industrial CCS activities, from storage-site selection, to environmental monitoring, to liability issues. And

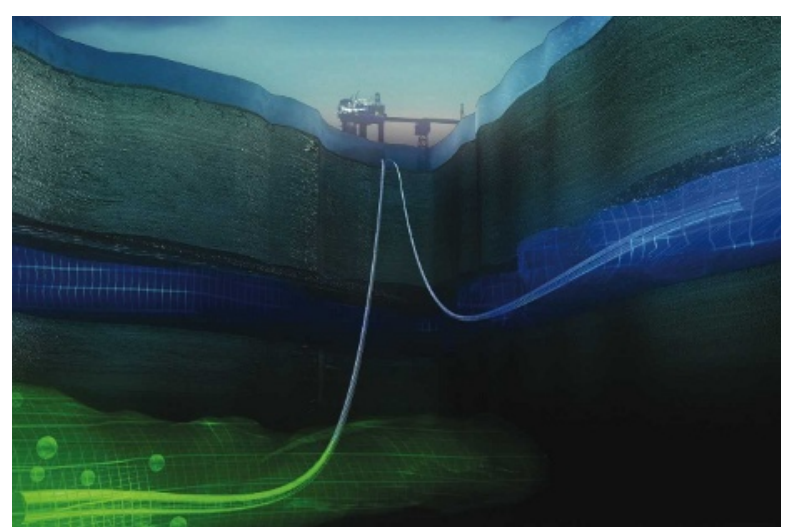

Europe has the world's only commercially viable carbon capture and storage facility - at a gas field in the North Sea. it ensures that $\mathrm{CO}_{2}$ captured and stored will be credited as not emitted under the European Union's mandatory emissions-trading scheme.

Economic incentives are vital to getting industry onboard, the European Commission believes. It hopes that if the costs of capturing $\mathrm{CO}_{2}$ become lower than the costs of releasing the gas into the atmosphere, industry will voluntarily switch to CCS technologies.

But the technology is not yet mature. Scrubbing $\mathrm{CO}_{2}$ from the gas stream is expensive and decreases the efficiency of coal-fired plants, so it is not yet commercially viable.

In a white paper also to be released next week, the commission will spell out measures and incentives for 'early movers' in the power industry. Among other things, financial aid worth up to $€ 1.5$ billion (US $\$ 2.2$ billion) could be provided to encourage industry to set up 10-12 demonstration facilities in the next decade. However, commission officials say they doubt that more than four or five demonstration plants will end up being built.

At the moment, in Europe, only Norway and Britain have concrete plans for pilot plants. The Norwegian company Statoil currently operates Europe's only commercial CCS project, in the Sleipner West natural-gas field in the North Sea. "There is still resistance in the power industry, but the amount of scepticism is waning compared to five years ago," says Frederic Hauge, vice-chair of the European Union's Technology Platform for Zero Emission Fossil Fuel Power Plants, which was established by the European Commission in 2005 and comprises scientists, industry and non-governmental organizations.

Meanwhile, China and the United States also plan to build large-scale demonstration plants in the next 10 years. An Illinois-based site for FutureGen, a \$1.5-billion public-private partnership to build a coal-fuelled near-zero-emissions power plant, was announced in December. This January, America began testing the safety, permanence and economic feasibility of storing large volumes of $\mathrm{CO}_{2}$ in geological structures at 22 test sites run by 7 regional partnerships, each comprising universities, state agencies and private companies.

Quirin Schiermeier 